Article

\title{
An Economic Analysis Algorithm for Urban Forestry Projects
}

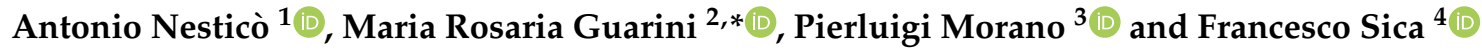 \\ 1 Department of Civil Engineering, University of Salerno, 84084 Fisciano (SA), Italy; anestico@unisa.it \\ 2 Department of Architecture and Design, "Sapienza" University of Rome, 00196 Rome, Italy \\ 3 Department of Science of Civil Engineering and Architecture, Polytechnic University of Bari, \\ 70125 Bari, Italy; pierluigi.morano@poliba.it \\ 4 Department of Architecture and Design, Doctoral School of Architecture and Construction, "Sapienza" \\ University of Rome, 00196 Rome, Italy; francesco.sica@uniroma1.it \\ * Correspondence: mariarosaria.guarini@uniroma1.it; Tel.: +39-347-3394586
}

Received: 9 November 2018; Accepted: 31 December 2018; Published: 9 January 2019

check for updates

\begin{abstract}
The second half of the 20th century was characterized by rapid growth of the urban population and lack of attention to environmental quality in the urbanizes territories. Thus, the development of many cities during that period took place through policies which, over time, resulted in a disaggregated landscape, both in morphological and functional terms. In some cases, these policies have caused the creation of land portions without a specific characterization, and the generation of urban voids that negatively affect the city's development. To solve this problem, the public administration sectors of many countries are looking for new intervention strategies that are feasible from a social and economic point of view which are able to guarantee sustainable development. From this perspective, the execution of urban regeneration initiatives, including forestation, allows for the improvement of both environmental quality and citizens' well-being, and promotes economic development. Considering the multiple effects that these initiatives can generate and the limited availability of public and private resources, it is appropriate to use multi-criteria decision support tools through which it is possible to evaluate the interventions' complexity and best identify the city areas that lend themselves to be recovered and improved through the forestation. The aim of this work is to develop a support tool for public administrations aimed at identifying the optimal forestry projects' location according to criteria that not only refer to financial type, but also their social, cultural, and environmental nature. Using Discrete Linear Programming algorithms, the model has been tested through a theoretical case study and reveals the advantages and limitations of the model, as well as future research prospects.
\end{abstract}

Keywords: sustainable development; urban renewal; urban forestry; ecosystem services; multicriteria analysis; Discrete Linear Programming

\section{Introduction}

Since the second half of the 20th century, the urban landscape of many cities has developed into a polycentric configuration in which there are often both areas with excessive building density, strong pollution, and high social disadvantage, as well as abandoned ones and others not only urbanized [1-4]. This situation has almost always caused a great difference between dissimilar parts of the same city, in terms of liveability, wealth, social equity, and environmental quality.

However, the presence in urban, often central contexts of free or partially built-up areas-hereon referred to as "degraded areas" —offers today the opportunity to reconnect the existing fabric on the 
basis of territory unitary development models that can be traced back to the Green City integrated principles [5-7].

In 2015, the United Nations (UN) Organization approved the Global Sustainable Development Agenda, where the 17 Sustainable Development Goals (SDGs) that Member States agreed to pursue by 2030 are defined [8]. Among these SDGs, one of which specifically has regard to sustainable cities, it is possible to identify some logical-functional relationships useful for determining optimal intervention policies from an integrated sustainable development perspective (Figure 1).

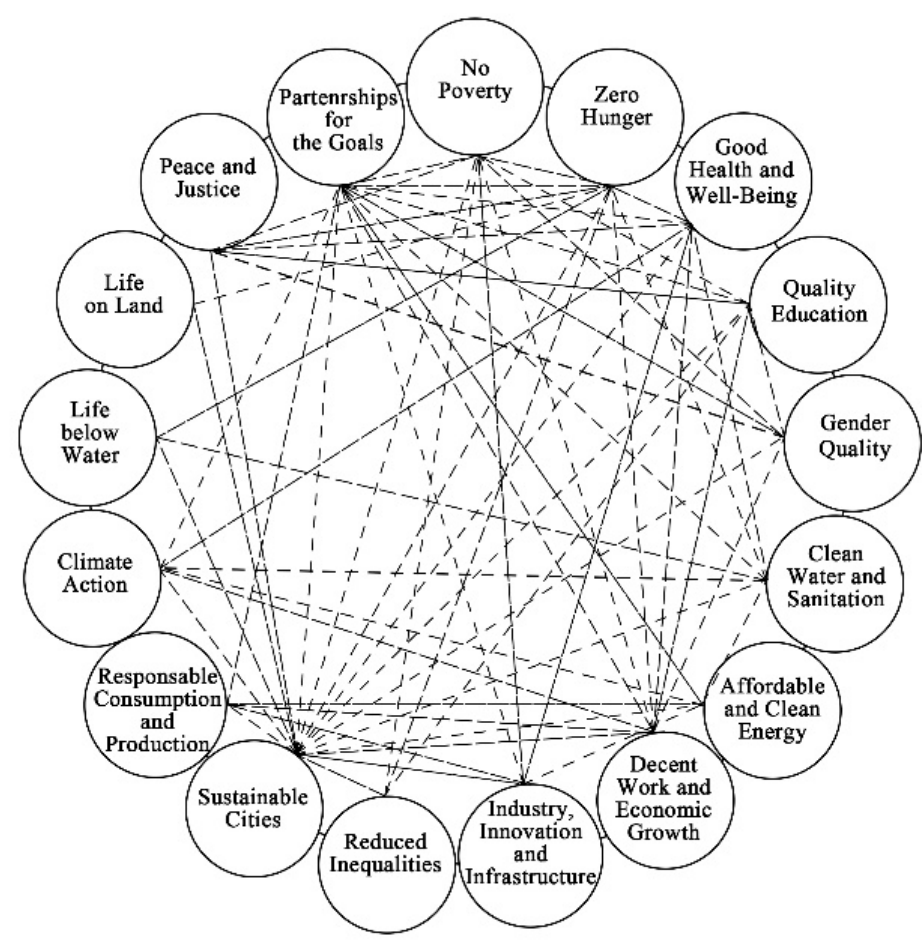

Figure 1. Relations system between Sustainable Development Goals.

To make cities sustainable, the European Commission is promoting the execution of integrated urban design initiatives [9] based on "ecologically sound urban design practices" [10]. These initiatives are urban regeneration actions aimed at recovering the existing fabric, creating green places, and providing infrastructures and services. In particular, the execution of recovery projects with the inclusion of new green spaces (urban forests) aims to raise the quality level of entire portions of urbanized territory [11]. Specifically, through renewal interventions that include urban forestry, it is possible to improve the consolidated urban contexts' quality not only of environmental type (for example, the atmospheric breakdown and acoustic pollution, the green spaces availability, the microclimate improvement, the protection of the biotic component of the place, the land use, the impermeability reduction of the soil), but also the social, cultural, and economic quality [12].

In some European countries, such as Finland and Belgium, in line with (a) the programmatic provisions contained in the Thematic Strategy for the Urban Environment [13] and (b) the main European Concerted Research Actions, such as the COST E12 Action (2005) "Urban Forest and Trees" [14] and the COST Action E39 (2006) "Forests, Trees and Human Health and Well-Being" [15], urban interventions are executed to protect and enhance the existing natural capital seen as a strategic resource for city development [16].

The effects generated on the territory by these integrated actions of urban valorization and qualification of urban green areas are multiple. These effects can be traced back to ecosystemic services on the basis of morphological and urban aspects of the intervention area $[17,18]$. According to classification provided by the Millennium Ecosystem Assessment (MEA) about ecosystem services types [19], the Food and Agriculture Organization (FAO) identified ten key issues to be used in the 
design phase of urban forestry interventions, as principles defined in terms of the place characteristics and objectives pursued [20]. Each of the key issues can be matched with a performance indicator, established on the basis of the status quo of the area in which the renewal projects, including urban forestry, can be implemented, following SDGs and the ecosystemic effects generated in the reference urban context, hereinafter "Ecosystemic Integrated Projects" (EIPs).

The decision to realize EIPs in "degraded areas" was based on three targets, which concerned the possibility of providing a recreational space for the residents (recreational targets) with respect to the area's morphological characteristics (structure-strengthening targets) and typological peculiarities of existing tree species (ecological targets) [16]. In this way, it is possible to recover "degraded areas" considering both the FAO's key issues and targets according to a logical-functional relationship of biunivocal correspondence (see Figure 2 of Section 3.1). This also enables us to identify those that represent a possible city development node among the possible areas to be redeveloped, according to urban forestry-integrated principles [21].

Therefore, the problem arises of the best location choice for the urban renewal project, based on financial, social, cultural, and environmental criteria [6]. These are decisional problems of which resolution requires the use of specific economic evaluation techniques. In the case of jointly taking into account various kinds of indicators, it is useful to apply multi-criteria economic evaluation techniques in order to express the multidimensional character of the examined problem [22-24].

Operationally, different tools are known in the literature that can implement economic evaluation models based on multi-criteria logic, often constructed to solve ranking and sorting problems, as well as through optimization procedures $[25,26]$. Depending on the evaluation question to be solved and the consequent indicators to be adopted, it is possible to select the most appropriate evaluation tool [27]. Among these, the Operations Research Algorithms, such as Goal Programming [26], can certainly be extremely useful, since they allow for solving complex decision-making schemes with a high number of variables and multiple objectives to be pursued simultaneously [26] - as in the case of Ecosystemic Integrated Projects (EIPs) - through the writing of linear algebraic relationships between parameters, while respecting the specific multiple constraints of the problem to be solved [28].

Although the multiple positive repercussions generated by actions based on ecosystemic logics are now recognized, this intervention modality is still not widely used in urban policies. This is both due to the interest of the public administration and private sectors, which prefer actions that generate an immediate consensus return and financial repercussions, and the difficulty of realizing EIPs on the basis of evaluations that consider the multidimensional aspects and the use of multi-criteria proper of this type of project in an integrated manner [29].

\section{Work Aims}

In line with the framework outlined previously, our research objectives were first concerned with the need to focus on the investors and public administrators' attention on the benefits of urban forestation projects for the redevelopment of degraded areas. Another more strictly operative objective consisted in defining an economic model which was able to select the areas to forest in an optimal manner, even in the presence of different kinds of constraints (technical, political, normative) and various stakeholders expressing conflicting interests and purposes. Thus, the sites, whose requalification made according to ecosystemic principles ensures the best result due to the availability of financial resources, the morphological characteristics, and the effect generated in the reference territorial context-assessed in terms of services offered to the community-were able to be identified.

In essence, starting from the set of available areas, financial resources, and effects that can be generated with forest interventions, we intended to define a decision support model for public administration technicians with which it was possible to:

- Generate a priorities list of the areas on which to implement the initiative due to the expected effects;

- generate favorite rational and awareness assessments; 
- improve the transparency of the choices, translating the constraints and programme objectives into mathematic relations.

The novelty of this study should also be noted. Research on this topic in the literature is not very numerous and is actually rather recent. Studies which do exist represent an initial approach to the subject, which is addressed only in quite general terms [30].

Regarding the model to be defined and which was tested in this piece of research, it should be noted that according to the intervention methods and available data, it is possible to use different tools that are able to take into account the multidimensional character of the initiatives relating to the requalification of portions-circumscribed territories conducted in line with the EIP model. In this work, the theory and algorithms of Operational Research, with which it is possible to solve complex decision problems, and characterized by numerous constraints and many variables, were used. In particular this model was developed by crossing the linear programming algorithms with multi-criteria decision analysis (MCDA), and implemented using the "A Mathematical Programming Language" (AMPL) software. It is a simple and intuitive tool used for structuring mathematical programming problems. Resolutions can be made with the use of specific softwares for optimization models (solvers). Some examples of these are CPLEX, FortMP, and KNITRO [31,32].

The model was tested by using a case study. The model's structure provides a general methodology that can be applied in complex planning cases. The model algorithm is easily adaptable to the specificity of various countries. This, through the writing of constraint relations, was defined according to the urban context of reference.

The remaining part of this paper is divided into four sections. In Section 3, the set of criteria that is defined and used for evaluating the intervention possibilities according to the objectives to be pursued and corresponding targets is outlined (Section 3.1), and a short background about Linear Programming principles is also provided, whereafter the decision support model is structured to optimize the financial resources allocation for EIPs that includes the forestation of urban fabric degraded areas (Section 3.2); in Section 4, the case study is illustrated and the model proposed is implemented, whereafter the results are explained; and in Section 5 the conclusions are reached.

\section{Materials and Methods}

\subsection{Set of Criteria for the Selection of Sites to Be Renewed with Urban Forestry Interventions}

In the case where there are degraded land portions which are poorly constructed or without a specific functional characterization, it may be useful to facilitate the execution of redevelopment interventions in the urban forestry ecosystemic principles. The general target benchmarks are the: psycho-physical wellbeing of citizens (recreational targets), existing natural component enhancement (ecological targets), and safeguarding of environmental, social, and cultural components of the area of interest (structure-strengthening targets) [6].

These targets are reflected in 14 evaluation criteria, identified by Van Elegem et al. (2002) (Figure 2c). These criteria can be used to formulate a complex judgment regarding the selection of territorial contexts that are best suited to being requalified. In fact, as illustrated in Figure 2, the 14 criteria allow for expression of the ability of the area to satisfy the key issues (Figure 2a) and pursue the targets through the use of appropriate indicators (Figure 2d).

In the literature, it appears that there are many indicators that express the criteria. In the case of forestry, these are indicators that are able to characterize the reference urban context to which the intervention reverts [17], and to express ecosystemic services of ecological-environmental [33-35], economic, social, and cultural [36] type.

Some indicators (e.g., number of inhabitants, accessibility, absence of heavy industry and road infrastructure, absence of recreation facilities, texture classes, presence of forests) are objective, and can be recognized and measured on the basis of detailed information regarding the reference urban context; on the other hand, the remaining indicators can be measured using an ordinal values scale, by 
assigning to each of them a score according to the capacity of an EIP that includes urban forestry, to generate economic-environmental repercussions in the territory.

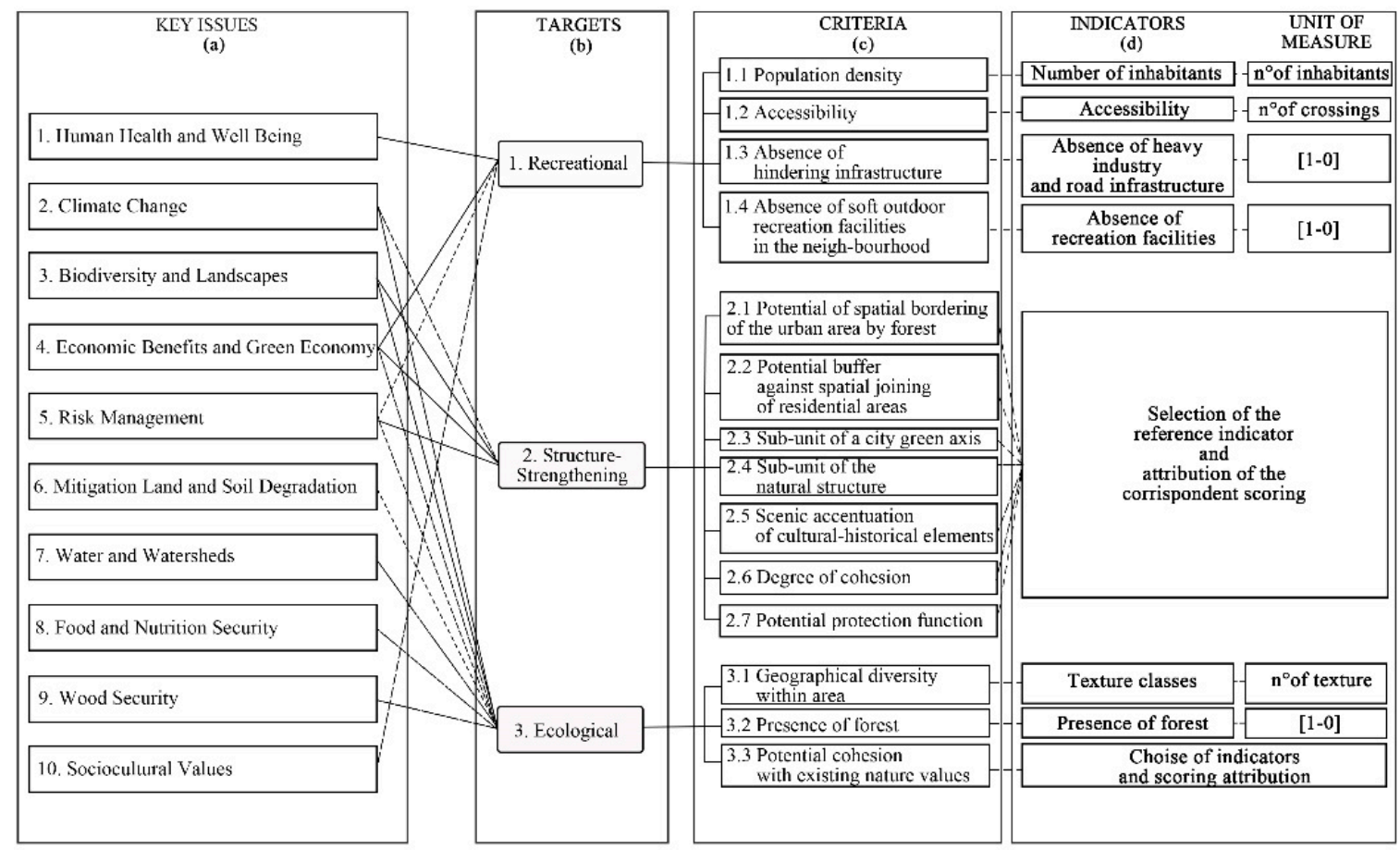

Figure 2. Logical sequence for the selection of evaluation indicators.

The logical scheme of Figure 2 allows to structure a multi-criteria evaluation model that can be used to facilitate the EIP execution in degraded areas, through the following phases:

1. Identification of the specific social, cultural, environmental, and financial objectives to be pursued;

2. selection of criteria and related performance indicators to express the achievement degree of the specific objectives set;

3. choice of the indicators selected on the basis of qualitative/quantitative information related to the reference urban context to the type of intervention proposed;

4. definition of the parameters and numerical data characteristics of the mathematical model related to the selection problem to be solved;

5. characterization of the mathematical model according to the logical-syntactic paradigms of mathematical programming software.

\subsection{The Optimization Algorithm}

For the definition of a model aimed at identifying the best urban area among those available to be used for redevelopment projects carried out according to ecosystemic principles of urban forestry, the Operational Research provides several algorithms, among which those of Linear Programming are most widely used.

In fact, complex problems, characterized by a high number of variables and constraint relations [37], as in the case of EIPs, are often solved using mathematical models structured according to goal programming. This is a methodology that helps to find an optimal solution by respecting the system constraints that characterize the problem to be solved. Starting from the second half of the last century, linear programming has been applied in numerous problems of project management [31,38-44] and land-use planning [45,46], as well as implementing geographic information systems [47-49], decision maps [50,51], urban-planning and economic project evaluation [52-55]. 
In particular, with reference to planning and urban regeneration, goal programming models are often used for the selection of the best project alternative between urban redevelopment interventions able to maximize the social welfare function [56-58], also referring to areas within strongly consolidated fabrics [59].

Again, some authors have used goal programming to develop a multi-criteria model to support revitalization strategies of the historic Alishan Forest Railway in Taiwan [60], or to characterize a model for urban regeneration interventions [61].

The development of an investment project has a number of similarities with the problem of Operational Research, which concerns the optimal allocation of scarce resources that can have alternative uses. In mathematical form, considering $m$ available resources which may have $n$ possible uses, the generic problem of operational research [62] is made of:

$$
\max (\mathrm{o} \min ) \mathrm{f}\left(x_{1}, x_{2}, \ldots, x_{n}\right)
$$

with the constraints (2):

$$
\left\{\begin{array}{c}
a_{11} \times x_{1}+a_{12} \times x_{2}+\cdots+a_{1 n} \times x_{n} \leq b_{1} \\
a_{21} \times x_{1}+a_{22} \times x_{2}+\cdots+a_{2 n} \times x_{n} \leq b_{2} \\
\cdots \\
a_{m 1} \times x_{1}+a_{m 2} \times x_{2}+\cdots+a_{m n} \times x_{n} \leq b_{m}
\end{array}\right.
$$

In Equations (1) and (2):

- $\mathrm{f}\left(x_{1}, x_{2}, \ldots, x_{n}\right)$ is the objective function to be maximized (max) or minimized (min);

- $\quad x_{1}, x_{2}, \ldots, x_{n}$ are the problem variables, on which the possible use of the resources depends;

- $\sum a_{i j} \times x_{i} \leq b_{i}(i=1, \ldots, m$ and $j=1, \ldots, n)$ defines the $i$-th constraint, where $a_{i j}$ is the rate of the $i$-th resource in the $j$-th use and $b_{i}$ is the $i$-th resource amount.

The functional relationships expressed in linear programming terms can be used to solve selection cases between design alternatives aimed at urban territory redevelopment [55,63-65], also with the implementation of Geographic Information Systems [47-49].

In these cases, these are often mathematical models characterized by the integer constraint $[x \in$ $\{0,1\}$ ] placed on the decision variables and resolved through the resolutive algorithms of Discrete Linear Programming (DLP). Among the most commonly used algorithms are those of dynamic programming, implicit enumeration (such as Branch \& Bound), cutting plane algorithms, and the Brunch \& Cut algorithm [66,67].

In the present study, since each design alternative (intervention area) should be considered as unitary, given the objective of establishing whether to use or exclude it, it was possible to use Discrete Linear Programming (DLP) algorithms [68].

The "A Mathematical Programming Language" (AMPL) software was used to structure the model. In practice, the use of the AMPL programming environment allows to write the selection problem through the following steps:

1. Identification of the problem elements (specific objectives in relation to targets, number of areas, evaluation criteria) as a set of objects;

2. specification of the problem parameters (budget, costs, multi-criteria evaluation matrix) to be included in the system;

3. definition of the variables' value (var $x$ binary);

4. structuring of the objective function as a linear algebraic expression that maximizes the ability to pursue the multiple purposes of urban forestry initiatives;

5. specification of the problem constraints to be solved. 
These steps define the structure of a model in parametric form (.mod file) to which the problem data are associated with a separately written .dat file.

On the basis of $m$ targets for projects based on ecosystemic principles, the problem arises of selecting, among the $n$ areas to be redeveloped, those most suitable to be transformed through urban forestry.

Each area, taken as the $x_{i}$ variable of the problem, was evaluated on the basis of $k$ evaluation criteria $(\mathrm{C})$ defined according to the target $m$-th to be reached. Considering both the project investment $\operatorname{cost} C_{i}$ for the $i$-th area and the available budget, the linear relations of the following mathematical system (3) are:

$$
\left\{\begin{array}{c}
\max \sum\left(\mathrm{C} 1.1_{i}+\cdots+\mathrm{C} 2.1_{i}+\mathrm{C} m \cdot k_{i}\right) \times x_{i} \\
\sum \mathrm{C}_{i} \times x_{i} \leq \mathrm{BUDGET} \\
x \in\{0,1\}(i=1, \ldots, n)
\end{array}\right.
$$

These mathematical relationships were implemented in the AMPL programming environment, as shown in Table 1 [69].

Table 1. The evaluation model written in "A Mathematical Programming Language" (AMPL) software (.mod file).

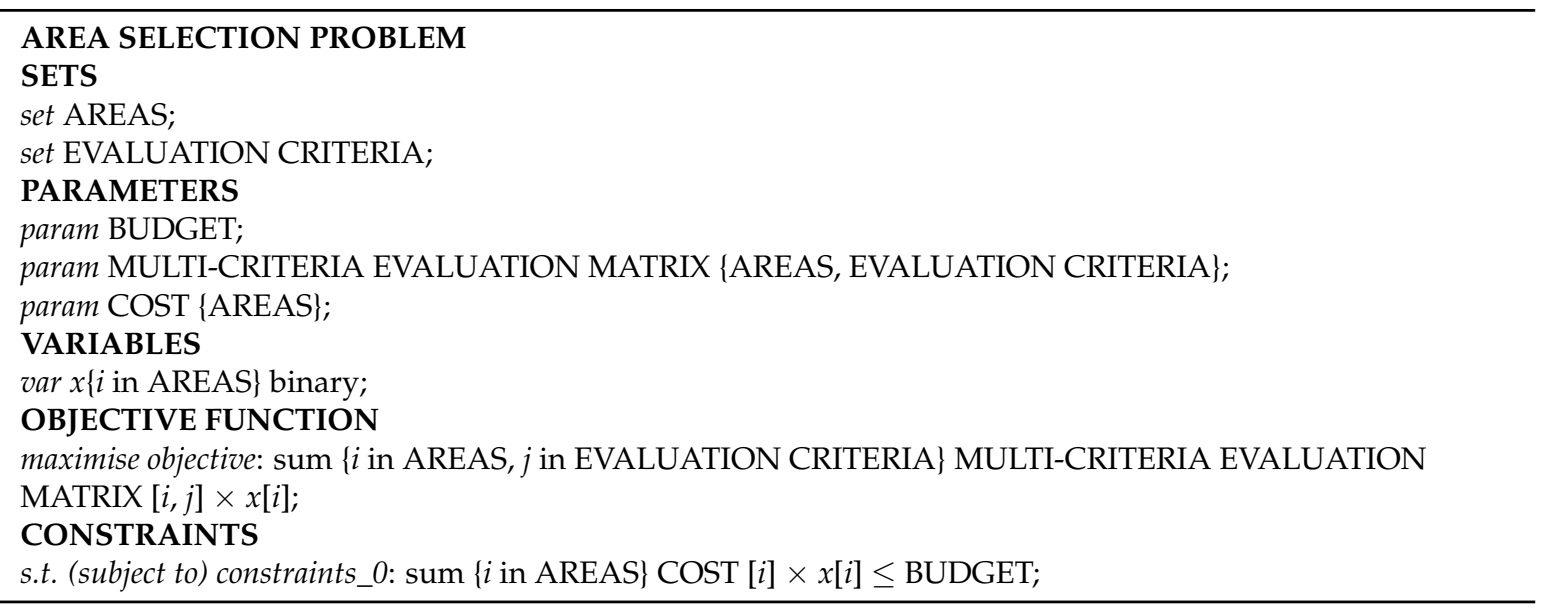

The $n$ areas on which EIPs are realized (set AREAS) were evaluated according to $k$ criteria (set EVALUATION CRITERIA), taking into account both morphological features of the place and the effects generated by the planned intervention.

The problem PARAMETERS were the:

- BUDGET,

- MULTI-CRITERIA EVALUATION MATRIX \{AREAS, EVALUATION CRITERIA\},

- $\operatorname{cosT}\{$ AREAS\}.

The unknowns are binary, namely $x \in\{0,1\}$.

The objective function is:

maximize objective: sum $\{i$ in AREAS, $j$ in EVALUATION CRITERIA $\}$ MULTI-CRITERIA EVALUATION MATRIX $[i, j] \times x[i]$.

The constraints system (COSTRAINTS) are to do with the financial allocation available:

s.t. constraint_0: sum $\{i$ in AREAS $\}$ COST $[i] \times x[i] . \leq$ BUDGET.

The CPLEX optimization program was used as a solver implementing the Brunch \& Cut (B \& C) algorithm to solve the Integer Linear Programming problems. 


\section{Results}

Case Study

For application of the proposed model, eight areas to be redeveloped through regeneration initiatives, including urban forestry actions, were assumed.

Due to the limited budget available - the imagined equivalent of $€ 1,000,000$, which does not allowfor the financing of all initiatives - the evaluation question expressed by the public administration sector was to select the areas able to generate the best financial, social, cultural, and environmental repercussions in the urban context within which they are proceeding, while using the available financial resources as best as possible.

Each area was evaluated according to following targets:

a. Improvement of the psycho-physical health of citizens,

b. Protection of the existing natural component,

c. Development of the environmental-economic context system,

all referable to the 14 criteria identified in Column C of Figure 2 used to express the degree of target achievement.

All 14 evaluation criteria and specific performance indicators were considered for case-study resolution.

For measurement of qualitative indicators, a values set $\{1,3,5\}$ was used, which made it possible to attribute an increasing score to the $i$-th area on the basis of the ability to pursue the target through the intervention.

The values of the indicators are illustrated in the multi-criteria analysis matrix of Table 2. This table also shows the investment cost of each project.

Table 2. Multi-criteria analysis matrix.

\begin{tabular}{|c|c|c|c|c|c|c|c|c|c|c|c|c|c|c|c|}
\hline \multirow[t]{2}{*}{ Area } & \multirow[t]{2}{*}{$\begin{array}{c}\text { Cost } \\
\text { (Thousand of } € \text { ) }\end{array}$} & \multicolumn{4}{|c|}{ Recreational Targets } & \multicolumn{7}{|c|}{ Structure-Strengthening Targets } & \multicolumn{3}{|c|}{$\begin{array}{c}\text { Ecological } \\
\text { Targets }\end{array}$} \\
\hline & & 1.1 & 1.2 & 1.3 & 1.4 & 2.1 & 2.2 & 2.3 & 2.4 & 2.5 & 2.6 & 2.7 & 3.1 & 3.2 & 3.3 \\
\hline 1 & 610 & 100 & 2 & 0 & 0 & 1 & 3 & 3 & 1 & 1 & 3 & 5 & 3 & 1 & 1 \\
\hline 2 & 480 & 120 & 3 & 0 & 0 & 3 & 5 & 5 & 5 & 5 & 3 & 5 & 5 & 0 & 1 \\
\hline 3 & 365 & 50 & 0 & 1 & 1 & 3 & 3 & 3 & 5 & 3 & 5 & 1 & 2 & 0 & 5 \\
\hline 4 & 200 & 95 & 0 & 0 & 1 & 1 & 3 & 5 & 3 & 5 & 1 & 1 & 1 & 0 & 3 \\
\hline 5 & 420 & 78 & 5 & 1 & 1 & 1 & 1 & 1 & 1 & 5 & 5 & 5 & 1 & 0 & 3 \\
\hline 6 & 300 & 150 & 2 & 0 & 0 & 3 & 1 & 3 & 5 & 1 & 3 & 3 & 3 & 1 & 1 \\
\hline 7 & 218 & 200 & 0 & 1 & 0 & 1 & 3 & 3 & 3 & 1 & 3 & 3 & 2 & 1 & 3 \\
\hline 8 & 122 & 0 & 1 & 1 & 0 & 1 & 5 & 1 & 1 & 3 & 1 & 5 & 5 & 0 & 5 \\
\hline
\end{tabular}

The model outlined in Section 3.2 was implemented with reference to data in Table 2. In the end, the .mod file of the analysis protocol was written such as in Table 3.

Table 3. The .mod file of the model.

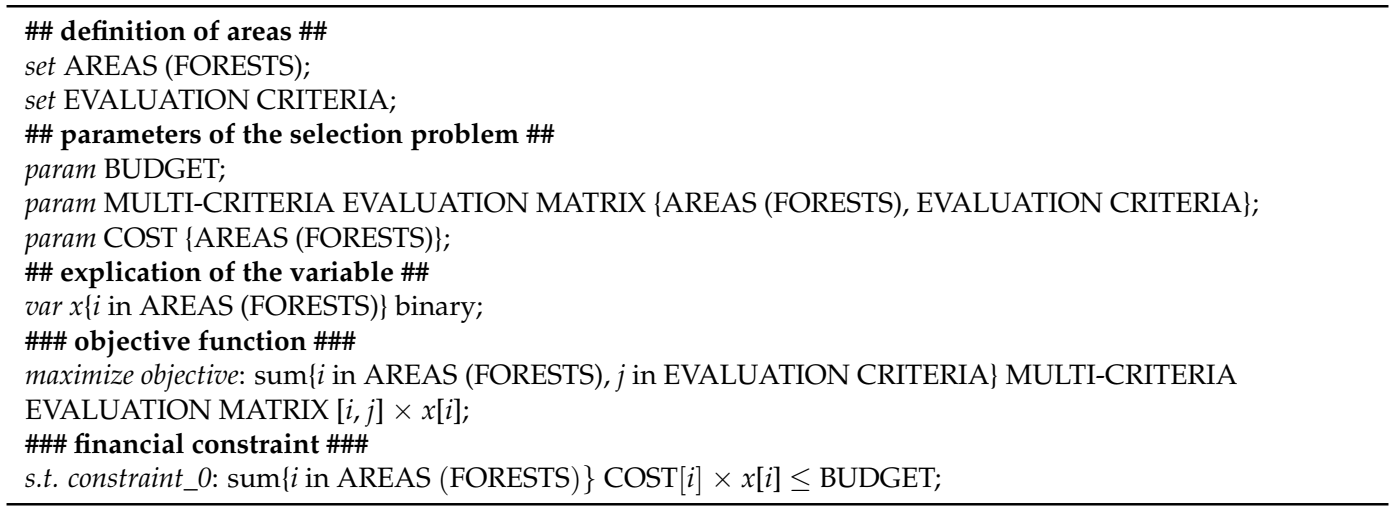


The .mod file in Table 3 associates with the .dat file in Table 4, which includes the multicriteria analysis data of Table 2.

Table 4. .dat file of the model written in AMPL.

\begin{tabular}{|c|c|c|c|c|c|c|c|c|c|c|c|c|c|c|c|}
\hline \multicolumn{16}{|c|}{$\begin{array}{l}\text { set AREAS (FORESTS) := } 1234567 \text { 8; } \\
\text { set EVALUATION CRITERIA := C1 C2 C3 C4 C5 C6 C7 C8 C9 C10 C11 C12 C13 C14; } \\
\text { param MULTI-CRITERIA EVALUATION MATRIX: }\end{array}$} \\
\hline & C1 & C2 & C3 & C4 & C5 & C6 & C7 & C8 & C9 & C10 & C11 & C12 & C13 & C14 & $:=$ \\
\hline 1 & 100 & 2 & 0 & 0 & 1 & 3 & 3 & 1 & 1 & 3 & 5 & 3 & 1 & 1 & \\
\hline 2 & 120 & 3 & 0 & 0 & 3 & 5 & 5 & 5 & 5 & 3 & 5 & 5 & 0 & 1 & \\
\hline 3 & 50 & 0 & 1 & 1 & 3 & 3 & 3 & 5 & 3 & 5 & 1 & 2 & 0 & 5 & \\
\hline 4 & 95 & 0 & 0 & 1 & 1 & 3 & 5 & 3 & 5 & 1 & 1 & 1 & 0 & 3 & \\
\hline 5 & 78 & 5 & 1 & 1 & 1 & 1 & 1 & 1 & 5 & 5 & 5 & 1 & 0 & 3 & \\
\hline 6 & 150 & 2 & 0 & 0 & 3 & 1 & 3 & 5 & 1 & 3 & 3 & 3 & 1 & 1 & \\
\hline 7 & 200 & 0 & 1 & 0 & 1 & 3 & 3 & 3 & 1 & 3 & 3 & 2 & 1 & 3 & \\
\hline 8 & 0 & 1 & 1 & 0 & 1 & 5 & 1 & 1 & 3 & 1 & 5 & 5 & 0 & $5 ;$ & \\
\hline \multicolumn{16}{|c|}{$\begin{array}{l}\text { param } \mathrm{BUDGET}:=1000 ; \\
\text { param COST }:=\end{array}$} \\
\hline \multicolumn{16}{|c|}{1610} \\
\hline \multicolumn{16}{|c|}{2480} \\
\hline \multicolumn{16}{|c|}{3365} \\
\hline \multicolumn{16}{|c|}{$4 \quad 200$} \\
\hline \multicolumn{16}{|c|}{$5 \quad 420$} \\
\hline \multicolumn{16}{|c|}{6300} \\
\hline \multicolumn{16}{|c|}{$7 \quad 218$} \\
\hline 8 & 122; & & & & & & & & & & & & & & \\
\hline
\end{tabular}

The .mod and .dat files are named within the AMPL command line (Table 5) in which the solver that implements the Branch \& Cut algorithm is specified.

Table 5. Command lines in AMPL.

ampl: reset;
ampl: model.mod FILE;
ampl: data.dat FILE;
ampl: option solver cplex;
ampl: solve.

Table 6 shows the results. The optimal combination is obtained with areas 2, 6 , and 7, whose urban forestry interventions make it possible to maximize the effects of the different nature that can be generated in the surrounding context and use the available financing in the best way possible, minimizing the unused portion of it that returns to the financial institution.

Table 6. Command lines in AMPL.

\begin{tabular}{|c|c|c|c|c|c|c|c|c|}
\hline \multicolumn{9}{|c|}{ ampl: display $x$} \\
\hline \multirow[t]{2}{*}{$x\left[{ }^{*}\right]:=$} & 1 & 2 & 3 & 4 & 5 & 6 & 7 & 8 \\
\hline & 0 & 1 & 0 & 0 & 0 & 1 & 1 & 0 \\
\hline \multicolumn{9}{|c|}{ ampl: objective function $:=560$} \\
\hline
\end{tabular}

\section{Conclusions}

A systemic vision between the natural and built environment suggests using alternative action strategies, with respect to those ordinarily pursued, in the redevelopment of degraded urban areas, addressing them in the context of the sustainable development of a city that harmoniously contemplates various financial, social, cultural, and environmental aspects. In this sense, interventions that include 
urban forestry actions are able to generate ecosystemic effects that can support the existing vegetation protection, economic growth of the territory, and the psycho-physical wellbeing of the citizens.

In cases where it is necessary to establish which-among those available-are the city portions to be redeveloped according to ecosystemic logics, it is important to have decision support tools that allow to identify the optimal allocation of the available financial resources in the functions of returns and eco-system services generated. According to the multidimensional nature of these initiatives, it is necessary to use the tools available to consider the complexity of the effects produced, obviously respecting the intrinsic characteristics of the area to be recovered.

In this work, an innovative multi-criteria model of Linear Discrete Programming was proposed and tested in order to define the optimal combination of interventions to be financed for sustainable urban development. The model can support the public administration sector in the planning of urban interventions defined according to integrated ecosystemic principles. For particularly complex cases characterized by numerous constraints and many variables, the model makes it possible to select the most suitable areas for urban forestry initiatives, as it is able to maximize the effects on the collective.

In order to express the various ecosystemic services generated by forestry actions, each intervention alternative is evaluated according to appropriate performance indicators. The use of multiple indicators makes it possible to select the best design solution based not only on financial parameters, but also social, cultural, and environmental ones. The result is the construction of an investment program defined in an effective and transparent manner, in line with the objectives of urban recovery and the enhancement of a natural and built environment.

The evaluation protocol, written with "A Mathematical Programming Language" in the .mod file, has input data derived from multicriteria analysis included in the dat file. These data are then implemented through the B\&C Optimization Algorithm, which resolves the optimization model composed of an objective function and which is subject to constraint conditions. The algorithm provides the best combination of the areas to be redeveloped through EIPs.

On the basis of the results obtained with the implementation of the proposed model, the set of areas $(2,6,7)$ returns the highest value of the objective function (560), and the sum of the corresponding investment costs ( $€ 998,000.00)$ responds to the constraint about the available budget $(€ 1,000,000.00)$.

Among the positive aspects of the model, the flexibility which derives from the nature of operational research, and thanks to which the mathematical relationships that translate the objectives and model constraints can be easily adapted to any changes in the technical, political, and economic context that could happen over time, should certainly be stressed.

In this sense, interesting research perspectives hold the possibility of modifying the model parameters to different urban realities, as well as the verifications relating to the concrete applicability of the model.

Author Contributions: A.N., M.R.G., P.M., F.S. have conceived, structured and written the article in equal part, as well as they have deepened review and editing the proposed article. In particular, A.N. and F.S. have implemented the software; M.R.G. and P.M. have validated the calculations; A.N. and M.R.G. have made work supervision.

Funding: This research received no external funding.

Conflicts of Interest: The authors declare no conflict of interest.

\section{References}

1. Godschalk, D.R. Land Use Planning Challenges: Coping with Conflicts in Visions of Sustainable Development and Livable Communities. J. Am. Plan. Assoc. 2007, 70, 5-13. [CrossRef]

2. El Din, H.S.; Shalaby, A.; Farouh, H.E. Principles of urban quality of life for a neighborhood. HBRC J. 2012, 9 , 86-92. [CrossRef]

3. European Commission. World and European Sustainable Cities: Insights from EU Research; 2010 EUR 24353 EN; Publications Office of the European Union: Luxembourg, 2010. 
4. $\quad$ European Commission. The State of European Cities: Cities Leading the Way to a Better Future; Publications Office of the European Union: Luxembourg, 2016; Available online: http:/ / ec.europa.eu/regional_policy/ sources/policy/themes/cities-report/state_eu_cities2016_en.pdf (accessed on 22 October 2018).

5. Kahnn, M.E. Green Cities. Urban Growth and the Environment; Brookings Institution Press: Washington, DC, USA, 2007; p. 150.

6. Koschke, L.; Fürst, C.; Frank, S.; Makeschin, F. A multi-criteria approach for an integrated land-cover-based assessment of ecosystem services provision to support landscape planning. Ecol. Indic. 2012, 21, 54-66. [CrossRef]

7. Jedliński, M. The position of green logistics in sustainable development of a smart green city. Procedia-Soc. Behav. Sci. 2014, 151, 102-111. [CrossRef]

8. Union Nations. Transforming Our World: The 2030 Agenda for Sustainable Development. A/RES/70/1. 2015. Available online: http://www.un.org/en/ga/search/view_doc.asp?symbol=A/RES/70/1 (accessed on 25 October 2018).

9. European Commission. Next Steps for a Sustainable European Future. European Action for Sustainability. COM. 2016. Available online: http:/ / ec.europa.eu/transparency/regdoc/rep/1/2016/EN/COM-2016-739F1-EN-MAIN.PDF (accessed on 16 October 2018).

10. Haughton, G.; Hunter, C. Sustainable Cities; Routledge: Abingdon, UK, 2004; p. 368.

11. Chiesura, A. The role of the urban parks for the sustainable city. Landsc. Urban Plan. 2004, 68, 129-138. [CrossRef]

12. Tyrväinen, L.; Pauleit, S.; Seeland, K.; de Vries, S. Benefits and uses of urban forests and trees. In Urban Forests and Trees; Springer: Berlin/Heidelberg, Germany, 2005; pp. 81-114.

13. European Commission. Thematic Strategy on the Urban Environment, COM. 2005. Available online: https:/ / eur-lex.europa.eu/legal-content/EN/TXT/HTML/?uri=CELEX:52005DC0718\&from=EN (accessed on 24 October 2018).

14. Konijnendijk, C.C.; Schipperijn, J.; Nilsson, K. Urban Forest and Trees-Proceedings No. 2; EU Publication Office (OPOCE): Brussels, Belgium, 2005.

15. Kjell, N.; Sangster, M.; Konijnendijk, C.C. Forests, trees and human health and well-being. In Forests, Trees and Human Health; Springer: Dordrecht, The Netherlands, 2011; pp. 1-19.

16. Van Elegem, B.; Embo, T.; Lust, N. A methodology to select the best locations for new urban forests using multicriteria analysis. Forestry 2002, 75, 13-23. [CrossRef]

17. Goméz-Baggenthum, E.; de Groot, R.; Lomas, P.L.; Montes, C. The history of ecosystem services in economic theory and practice: From early notions to markets and payment schemes. Ecol. Econ. 2009, 69, 1209-1218. [CrossRef]

18. Sanesi, G.; Gallis, C.; Kasperidus, H.D. Urban Forests and Their Ecosystem Services in Relation to Human Health. In Forests, Trees and Human Health; Springer: Dordrecht, The Netherlands, 2011; pp. 23-40.

19. Millennium Ecosystem Assessment. Ecosystems and Human Well-Being: Synthesis; Island Press: Washington, DC, USA, 2005.

20. FAO. Guidelines on Urban and Peri-Urban Forestry; Salbitano, F., Borelli, S., Conigliaro, M., Chen, Y., Eds.; FAO Forestry Paper No. 178; Food and Agriculture Organization of the United Nations: Rome, Italy, 2016; Available online: http:/ / www.fao.org/3/a-i6210e.pdf (accessed on 23 October 2018).

21. Bossuyt, B.; Hermy, M. Restoration of the understory layer of recent forest bordering ancient forest. Appl. Veg. Sci. 2000, 3, 43-50. [CrossRef]

22. Morano, P.; Locurcio, M.; Tajani, F.; Guarini, M.R. Urban Redevelopment: A Multi-criteria Valuation Model Optimized through the Fuzzy Logic. In Computational Science and Its Applications-ICCSA 2014; Murgante, B., Ed.; ICCSA 2014. Lecture Notes in Computer Science; Springer: Cham, Switzerland, 2014; Volume 8581, pp. 161-175. [CrossRef]

23. Morano, P.; Locurcio, M.; Tajani, F.; Guarini, M.R. Fuzzy logic and coherence control in multi-criteria evaluation of urban redevelopment projects. Int. J. Bus. Intell. Data Min. 2015, 10, 73-93. [CrossRef]

24. Torre, C.M.; Morano, P.; Tajani, F. Saving soil for sustainable land use. Sustainability 2017, 9, 350. [CrossRef]

25. Roy, B. The optimisation problem formulation: Criticism and overstepping. J. Oper. Res. Soc. 1981, 32, 427-436. [CrossRef]

26. Ishizaka, A.; Nemery, P. Multi-Criteria Decision Analysis: Methods and Software; John Wiley \& Sons: Hoboken, NJ, USA, 2013. 
27. Guarini, M.R.; Battisti, F.; Chiovitti, A. Public initiatives of settlement transformation: A theoreticalmethodological approach to selecting tools of multi-criteria decision analysis. Buildings 2017, 1, 1. [CrossRef]

28. Guitouni, A.; Martel, J.M.; Vincke, P.; North, P.B. A Framework to Choose a Discrete Multicriterion Aggregation Procedure; Defence Research Establishment Valcatier (DREV): Ottawa, ON, Canada, 1998.

29. European Commission. An Urban Agenda for the EU Panorama. 2016. Available online: http:/ / ec.europa. eu/regional_policy/sources/docgener/panorama/pdf/mag58/mag58_en.pdf (accessed on 2 October 2018).

30. Guarini, M.R.; Nesticò, A.; Morano, P.; Sica, F. A Multicriteria Economic Analysis Model for Urban Forestry Projects. In International Symposium on New Metropolitan Perspectives; Springer: Cham, Switzerland, 2018; pp. 564-571. [CrossRef]

31. Kaiser, M.G.; Arbi, F.El.; Ahlemann, F. Successful project portfolio management beyond project selection techniques: Understanding the role of structural alignment. Int. J. Proj. Manag. 2015, 33, 129-139. [CrossRef]

32. Applegate, D.L.; Cook, W.; Dash, S.; Espinoza, D.G. Exact solutions to linear programming problems. Oper. Res. Let. 2007, 35, 693-699. [CrossRef]

33. Clark, J.R.; Matheny, N.P.; Cross, G.; Wake, V. A model of urban forest sustainability. J. Arboric. 1997, 23, $17-30$.

34. Dobbs, C.; Escobedo, F.J.; Zipperer, W.C. A framework for developing urban forest ecosystem services and goods indicators. Landsc. Urban Plan. 2011, 99, 196-206. [CrossRef]

35. Kenney, W.A.; Van Wassenaer, P.J.; Satel, A.L. Criteria and indicators for strategic urban forest planning and management. Arboric. Urban For. 2011, 37, 108-117.

36. Barron, S.; Sheppard, S.R.J.; Condo, P.M. Urban Forest Indicators for Planning and Designing Future Forests. Forests 2016, 7, 208. [CrossRef]

37. Walker, R.C. Introduction to Mathematical Programming; Prentice Hall: Upper Saddle River, NJ, USA, 2001.

38. Markowitz, H.M. Portfolio selection. J. Financ. 1952, 7, 77-91.

39. Roberts, F.S. Discrete Mathematical Models with Applications to Social, Biological and Environmental Problems; Prentice-Hall: Upper Saddle River, NJ, USA, 1976.

40. Dallocchio, M. Finanza d'azienda. In Analisi e Valutazioni per le Decisioni D'impresa; EGEA: Milano, Italy, 1995.

41. Farragher, E.J.; Kleiman, R.T. A re-examination of real estate investment decision making practice. J. Real Estate Portf. Manag. 1996, 2, 31-39.

42. Cooke-Davies, T. The "real" success factors on projects. Int. J. Proj. Manag. 2002, 20, 185-190. [CrossRef]

43. Olson, D.L. Multiple Criteria Optimization: Theory, Computation, and Application; Wiley Series in Probability and Mathematical Statistics Applied; Willey: New York, NY, USA, 1996.

44. Elton, E.; Gruber, M.; Brown, S.; Goetzmann, W. Modern Portfolio Theory and Investment Analysis, 6th ed.; John Wiley and Sons: Hoboken, NJ, USA, 2003.

45. Chuvieco, E. Integration of linear programming and GIS for land-use modelling. Int. J. Geogr. Inf. Sci. 1993, 7, 71-83. [CrossRef]

46. Aerts Jeroen, C.J.H.; Eisinger, E.; Heuvelink Gerard, B.M.; Stewart Theodor, J. Using Linear Integer Programming for Multi-Site Land-Use Allocation. Geogr. Anal. 2003, 35, 148-169. [CrossRef]

47. Church, R.L. Geographical information systems and location science. Comput. Oper. Res. 2002, $29,541-562$. [CrossRef]

48. Shirabe, T. A model of Contiguity for Spatial Unit Allocation. Geogr. Anal. 2005, 37, 2-16. [CrossRef]

49. Ligmann-Zielinska, A.; Church Richard, L.; Jankowski, P. Spatial optimization as a generative technique for sustainable multiobjective land-use allocation. Int. J. Geogr. Inf. Sci. 2008, 22, 601-622. [CrossRef]

50. Stewart, J.T.; Janssen, R.; Van Herwijnen, M. A genetic algorithm approach to multiobjective land use planning. Comput. Oper. Res. 2004, 31, 2293-2313. [CrossRef]

51. Dias, L.C.; Mousseau, V. IRIS: A DSS for multiple criteria sorting problems. J. Multi-Criteria Decis. Anal. 2005, 12, 1-14. [CrossRef]

52. Esposito, E.; Rostirolla, P. Problema decisionale e tecniche di aiuto alla decisione. In I Beni Culturali. Linee Guida di Programmazione e di Valutazione dei Progetti; AA.VV.; Strumenti Formez n.6; Formez: Rome, Italy, 1993.

53. Rosato, P. Un modello di analisi multicriteri per la localizzazione di infrastrutture lineari in aree ad insediamento diffuso. Aestimum 2009, 36, 1998.

54. Dantzig, G. Linear Programming and Extensions; Princeton University Press: Princeton, NJ, USA, 2016.

55. Nesticò, A.; Sica, F. The sustainability of urban renewal projects: A model for economic multi-criteria analysis. J. Prop. Invest. Financ. 2017, 35, 397-409. [CrossRef] 
56. Ben-Shahar, H.; Mazor, A.; Pines, D. Town planning and welfare maximization: A methodological approach. Reg. Stud. 1969, 3, 105-113. [CrossRef]

57. Lee, C. Models in Planning; Pergamon Press: Oxford, UK, 1973.

58. Lee, S.M.; Keown, A.J. Integer goal programming model for urban renewal planning. Urban Syst. 1979, 4, 17-26. [CrossRef]

59. Courtney, J.F., Jr.; Klastorin, T.D.; Ruefli, T.W. A Goal Programming Approach to Urban-Suburban Location Preferences. Manag. Sci. 1972, 18, B-258. [CrossRef]

60. Chang, Y.H.; Wey, W.M.; Tseng, H.Y. Using ANP priorities with goal programming for revitalization strategies in historic transport: A case study of the Alishan Forest Raiway. Exp. Syst. Appl. 2009, 36, 8682-8690. [CrossRef]

61. Tajani, F.; Morano, P. Evaluation of vacant and redundant public properties and risk control: A model for the definition of the optimal mix of eligible functions. J. Prop. Investig. Financ. 2017, 35, 75-100. [CrossRef]

62. Korte, B.; Fonlupt, J.; Vygen, J. Optimisation Combinatoire: Theorie et Algorithms; Springer: Berlin, Germany, 2010.

63. Chakhar, S.; Mousseau, V.; Pusceddu, C.; Bernanrd, R. Decision map for spatial decision making in urban planning. In Proceedings of the Ninth International Conference on Computers in Urban Planning and Urban Management, London, UK, 29 June-1 July 2005; pp. 1-18.

64. De Mare, G.; Nesticò, A.; Tajani, F. Building Investments for the Revitalization of the Territory: A Multisectoral Mode of Economic Analysis. In Proceedings of the International Conference on Computational Science and Its Applications, Ho Chi Minh City, Vietnam, 24-27 June 2013; pp. 493-508.

65. Nesticò, A.; De Mare, G. Government Tools for Urban Regeneration: The Cities Plan in Italy. A Critical Analysis of the Results and the Proposed Alternative. In Proceedings of the International Conference on Computational Science and Its Applications, Trieste, Italy, 3-6 July 2014; pp. 547-562. [CrossRef]

66. Ventura, P. Alcuni Contributi alla Separazione Primale e Duale per Problemi di Programmazione Lineare Intera; Serie 8; Vol. 6-A-La Matematica nella Società e nella Cultura, 2; Bollettino dell'Unione Matematica Italiana: Jakarta, Indonesia, 2003; pp. 335-338.

67. Vercellis, C. Ottimizzazione: Teoria, Metodi, Applicazioni; McGraw-Hill: Milano, Italy, 2008.

68. Thuesen, G.J.; Fabrycky, W.J. Economia per Ingegneri; Il mulino-Prentice Hall: Bologna, Italy, 1994.

69. Bruglieri, M.; Cordone, R.; Liberti, L.; Iuliano, C. Manuale Essenziale di AMPL; Dipartimento di Elettronica e Informazione, Politecnico di Milano: Milano, Italy, 2010. 